\title{
Review \\ Effects of Cannabis Use on Human Behavior, Including Cognition, Motivation, and Psychosis: A Review
}

Nora D. Volkow, MD; James M. Swanson, PhD; A. Eden Evins, MD; Lynn E. DeLisi, MD; Madeline H. Meier, PhD; Raul Gonzalez, PhD; Michael A. P. Bloomfield, MRCPsych; H. Valerie Curran, PhD; Ruben Baler, PhD

With a political debate about the potential risks and benefits of cannabis use as a backdrop, the wave of legalization and liberalization initiatives continues to spread. Four states (Colorado, Washington, Oregon, and Alaska) and the District of Columbia have passed laws that legalized cannabis for recreational use by adults, and 23 others plus the District of Columbia now regulate cannabis use for medical purposes. These policy changes could trigger a broad range of unintended consequences, with profound and lasting implications for the health and social systems in our country. Cannabis use is emerging as one among many interacting factors that can affect brain development and mental function. To inform the political discourse with scientific evidence, the literature was reviewed to identify what is known and not known about the effects of cannabis use on human behavior, including cognition, motivation, and psychosis.

JAMA Psychiatry. doi:10.1001/jamapsychiatry.2015.3278

Published online February 3, 2016.

\author{
Author Affiliations: Author \\ affiliations are listed at the end of this \\ article. \\ Corresponding Author: Nora D. \\ Volkow, MD, National Institute on \\ Drug Abuse, National Institutes of \\ Health, 6001 Executive Blvd, \\ Bethesda, MD 20892 \\ (nvolkow@nida.nih.gov).
}

$\mathrm{I}$ $\mathrm{t}$ is well established that cannabis use causes acute impairment in the ability of the brain to hold information (ie, cognitive capacity). Hence, temporary deficits occur in learning and memory, attention, and working memory.

\section{Does Cannabis Use Affect Cognitive Capacity?}

Cannabis use causes acute impairment of learning and memory, attention, and working memory, ${ }^{1-3}$ but it is less clear if cannabis use is associated with enduring neuropsychological impairment. Casecontrol studies comparing nonintoxicated heavy cannabis users with nonusers have fairly consistently shown that heavy cannabis users perform worse on neuropsychological tests. For example, the results from 2 separate meta-analyses ${ }^{4,5}$ showed that compared with nonusers, nonintoxicated cannabis users perform worse on measures of global neuropsychological function, with effect sizes for specific neuropsychological domains (executive functions, attention, learning and memory, motor skills, and verbal abilities) of approximately onethird of a standard deviation or less. When analyses in the second meta-analysis ${ }^{5}$ were limited to 13 studies of cannabis users with at least 1 month of abstinence, there was no discernible difference between cannabis users and nonusers on neuropsychological test performance, suggesting that neuropsychological functions might recover with prolonged abstinence. Evidence suggests that the magnitude of neuropsychological impairment and the extent to which it persists after abstinence may depend on the frequency and duration of cannabis use, length of abstinence, and age at onset of use. ${ }^{6}$

Emerging evidence suggests that adolescents may be particularly vulnerable to the adverse effects of cannabis use. Adolescence represents a critical neurodevelopmental period characterized by marked synaptic pruning and increased myelination. ${ }^{7}$
Moreover, the endocannabinoid system appears to be involved in the regulation of key neurodevelopmental processes, ${ }^{7}$ suggesting that the introduction of exogenous cannabinoids during adolescence could disrupt normal brain development. Animal research supports the possibility that adolescence represents a period of heightened vulnerability to cannabis exposure. ${ }^{7}$ For example, pubertal rats treated with a cannabinoid agonist showed persistent deficits on object recognition tasks, whereas adult rats did not. ${ }^{8,9}$ Accumulating evidence in humans parallels the animal findings. ${ }^{6}$ For example, several studies have shown that earlier age at onset of cannabis use is associated with greater neuropsychological impairment, ${ }^{10,11}$ and a 2012 population-representative longitudinal study ${ }^{12}$ documented that adolescent-onset (but not adult-onset) persistent cannabis users showed neuropsychological decline from ages 13 to 38 years.

Neuroimaging investigations of adolescent and adult cannabis users have yielded somewhat inconsistent findings. Recent reviews have demonstrated that there is fairly clear evidence of structural alterations in medial temporal (amygdala and hippocampus), frontal, and cerebellar regions associated with cannabis exposure. ${ }^{13,14}$ However, another recent study ${ }^{15}$ that carefully matched participants on alcohol intake reported no evidence of morphological brain alteration among adolescent or adult cannabis abusers, suggesting the possibility that comorbid alcohol use could explain some of the morphological alterations observed in prior research. There is also some evidence that cannabis users have impaired neural connectivity. For example, a study ${ }^{16}$ of adults with long histories of heavy cannabis use showed evidence of decreased connectivity in the right fimbria of the hippocampus (fornix) and the splenium of the corpus callosum and the commissural fibers. Finally, functional magnetic resonance imaging investigations have suggested that cannabis users show altered neural activity both in the resting state and during cognitive testing. ${ }^{14}$ For example, male adolescent cannabis 
users showed increased blood oxygen level-dependent functional magnetic resonance imaging activity in the prefrontal cortex during a novel working memory task, which was interpreted to reflect inefficient processing. ${ }^{17}$ This observation is consistent with studies measuring resting functional connectivity in adolescent cannabis users that have documented altered patterns of connectivity affecting interhemispheric traffic ${ }^{18}$ and the frontotemporal network. ${ }^{19,20}$ Some evidence suggests that cannabidiol, another cannabinoid found in the cannabis plant (although usually at very low concentrations), may protect against some of the harmful effects of tetrahydrocannabinol (THC) on cognition. ${ }^{21,22}$

There are areas that require further research. First, observed differences in neuropsychological test performance, as well as in brain structure and function, might reflect individual differences that precede cannabis use. Progress has been limited by reliance on crosssectional investigations comparing cannabis users and nonusers. Two longitudinal studies ${ }^{12,23}$ with before-and-after neuropsychological testing have shown evidence of within-individual decline in neuropsychological function associated with cannabis use. The findings could not be explained by alcohol and other drug use, psychiatric disorders, low socioeconomic status, or a host of other potential confounds. However, the number of cannabis users in these cohorts was small, and brain imaging was not performed. Yet, neuroimaging findings raise the possibility that smaller regional brain volumes among cannabis users could be partially accounted for by preexisting differences. For example, one prospective longitudinal study ${ }^{24}$ showed that smaller orbitofrontal cortex volumes increased risk for adolescent cannabis use initiation, while a study ${ }^{25}$ of twins and siblings found that reduced amygdala volumes among cannabis users could be explained by familial factors. Taken together, these findings highlight the need for longitudinal studies that follow up adolescents from before to after initiation of cannabis use and combine neuropsychological testing with neuroimaging. The Adolescent Brain Cognitive Development Study, ${ }^{26}$ a large prospective National Institutes of Health-funded investigation of children ages 9 to 10 years who will be followed up for at least 10 years, is being launched to in part meet this need.

A second area that is ripe for further research pertains to the need to reconcile neuroimaging findings with neuropsychological test performance. Current neuroimaging evidence is inconsistent, and alterations in brain structure and function tend not to correlate with decrements in neuropsychological test performance. ${ }^{27}$ Larger samples are needed for imaging along with careful consideration of participant characteristics, including comorbid use of alcohol and other drugs and length of abstinence from cannabis.

Third, more work is needed to answer the question "How much cannabis use is too much?" Because many study samples include a large portion of individuals with cannabis dependence (as defined by the $D S M-I V$ ), it is unclear if the effects generalize to individuals with less severe cannabis use disorders and to more casual recreational users.

Fourth, because of the potential effect of exogenous cannabinoids on brain development, more work is needed to answer the question "At what age is cannabis use most harmful?" In addition to studying the effects of cannabis use on adolescents, research is also needed to understand older adults' susceptibility to cannabisrelated neuropsychological impairment. This population experiences changes in brain plasticity and age-related cognitive decline that may make them more vulnerable to the effects of cannabis use.
Fifth, recent evidence suggests sex differences in neuropsychological deficits associated with cannabis use. ${ }^{1,28}$ Hence, future work should help clarify mechanisms underlying these potential sex differences.

Sixth, genetic factors such as polymorphisms in the COMT (OMIM 116790) and AKT1 (OMIM 164730) genes may also increase susceptibility to cannabis-related neuropsychological impairment. ${ }^{29}$ Other examples include a recent study ${ }^{30}$ that showed that THC caused acute impairment of working memory for COMT Val/Val carriers (but not Met carriers), as well as another study ${ }^{31}$ of 3 populationbased cohorts that showed that cannabis use was associated with decreased cortical thickness among male individuals at high (but not low) genetic risk for schizophrenia as indexed by a polygenic risk score. The possibility that individual differences among cannabis users may have significant effects and be predictive of the extent of adverse consequences suggests that recent approaches to leveraging genetic information to create polygenic risk scores might be useful toward advancing the study of cannabis use and neuropsychological function.

\section{Does Cannabis Use Decrease Motivation?}

As early as the late 19th century, the Indian Hemp Drugs Commission ${ }^{32}$ reported that heavy cannabis use was associated with apathy, defined as reduced motivation for goal-directed behavior. ${ }^{33}$ However, it was only after the marked increase in cannabis use of the 1960s that the amotivational effects of chronic cannabis use were linked to impairments in learning and sustained attention. The term cannabis amotivational syndrome was proposed by McGlothlin and West, ${ }^{34}$ who characterized it as apathy and diminished ability to concentrate, follow routines, or successfully master new material. While there has always been some controversy around the need for defining such a distinct phenotype, there is evidence that long-term heavy cannabis use is associated with educational underachievement and impaired motivation, which have been proposed to be potential mediators of poorer functional outcomes. ${ }^{35}$

There is both preclinical and clinical evidence supporting the view that cannabis use is associated with an amotivational state. In rhesus monkeys, heavy chronic cannabis use or administration has been found to dampen motivation, as measured on progressive ratio and conditioned position responding operant tests. ${ }^{36}$ There is preliminary laboratory evidence supporting an association between reduced motivation for reward-related behavior in cannabis users compared with control individuals. ${ }^{37}$ Because these findings appear to be related to repeated doses of THC, it is likely that reduced motivation is one pathway to impaired learning, as THC can disrupt reward-based learning. ${ }^{38}$ In support of this theory, cannabis users exhibit reduced striatal dopamine synthesis capacity, ${ }^{39}$ with an inverse relationship to amotivation. Inasmuch as dopamine signaling sustains motivation, ${ }^{40}$ impaired dopamine synthesis could underlie the amotivational state in cannabis users. Similarly, imaging investigations documented decreased reactivity to dopamine stimulation in cannabis users that was associated with negative emotionality and that would also contribute to reduce engagement in non-drug-related activities. ${ }^{41}$

Amotivation in chronic heavy users may also reflect the fact that cannabis itself has become a major motivator, so other activities (eg, 
schoolwork) become demoted in the individual's reward hierarchy. Indeed, addiction to the drug occurs in about $9 \%$ of users ${ }^{42}$ who appear more vulnerable than other users because of a multiplicity of variables, including age at onset, level of use, and environmental and genetic factors.

What remains to be seen is whether changes in the concentration of the active ingredients of cannabis could affect the risk of amotivation or addiction. The cannabis plant contains approximately 100 unique cannabinoid ingredients, with the most researched being THC and cannabidiol. Over the last 30 years, levels of THC in street cannabis have increased. ${ }^{43}$ Of these 2 compounds, only THC determines the level of the subjective high. Alongside a blunted dopamine system, ${ }^{41}$ chronic heavy use of cannabis is associated with changes in the endocannabinoid system, including reduced levels of anandamide (an endogenous ligand for the cannabinoid receptors) in human cerebrospinal fluid ${ }^{44}$ and reduced levels of cannabinoid 1 receptors. ${ }^{45}$ Indeed, a growing preclinical literature implicates cannabinoid 1 receptors and their endogenous ligands in the motivational effects of cannabis use. ${ }^{46}$ Similar to the association of cannabis use with cognitive impairment, it is impossible to unambiguously establish whether cannabis use is a cause, consequence, or correlate of altered motivation. Further work is needed to distinguish whether the potential amotivational effects are related to cannabis use disorders rather than cannabis use per se.

\section{Does Cannabis Use Increase the Risk for Psychosis?}

One of the most persistent controversies vis-à-vis cannabis use pertains to its effect on the risk of psychiatric disorders, particularly psychotic disorders and full-blown schizophrenia. Longitudinal investigations show a consistent association between adolescent cannabis use and psychosis. Cannabis use is considered a preventable risk factor for psychosis. ${ }^{47}$ The link between cannabis use and schizophrenia could stem from direct causality, gene-environment interactions, shared etiology, or self-medication for premorbid symptoms, although some researchers have suggested that only the first 3 hypotheses remain open questions. ${ }^{48-50}$ The sporadic emergence of conflicting data should not be surprising given the nature of this particular biological problem. For example, the effects of cannabis exposure may be modest in the total population and contingent on the presence of multiple genetic and environmental variables. On the other hand, there remains a lingering and legitimate controversy over what proportion of psychosis risk can be attributed to cannabis use and the extent to which individuals without genetic predisposition can be precipitated into the illness.

Despite this ambiguity, there is strong physiological and epidemiological evidence supporting a mechanistic link between cannabis use and schizophrenia. Tetrahydrocannabinol (particularly at high doses) can cause acute, transient, dose-dependent psychosis (schizophrenia-like positive and negative symptoms). ${ }^{51}$ In addition, prospective, longitudinal, epidemiological studies consistently report an association between cannabis use and schizophrenia in which cannabis use precedes psychosis ${ }^{52}$ independent of alcohol consumption ${ }^{53}$ and even after removing ${ }^{52,54}$ or controlling for ${ }^{55,56}$ those individuals who had used other drugs. Although the prodromal period before full-blown illness complicates determining whether or not cannabis use precedes symptoms or reflects an attempt to treat them, cannabis use preceded psychosis in these studies. ${ }^{52,54,57}$ Moreover, persistent cannabis use after a first episode is associated with poorer prognosis ${ }^{58}$ even after controlling for other substance use. ${ }^{59}$

Although cannabis use may have long been discontinued before the onset of psychosis, the age at which cannabis use begins appears to correlate with the age at onset of psychosis, suggesting a causal relationship to initiating psychosis that is independent of actual use. ${ }^{49,60,61}$ The association between cannabis use and chronic psychosis (including a schizophrenia diagnosis) is stronger in those individuals who have had heavy or frequent cannabis use during adolescence, ${ }^{53,54,60,62,63}$ earlier use, ${ }^{52}$ or use of cannabis with high THC potency. ${ }^{60,62}$ From these studies, ever use of cannabis is estimated to increase the risk of schizophrenia by approximately 2 -fold, accounting for $8 \%$ to $14 \%$ of cases, ${ }^{55}$ with frequent use or use of cannabis with high THC potency increasing the risk of schizophrenia 6 -fold. ${ }^{53}$ Consistent with this notion, the greater cannabinoid receptor type 1 availability that has been reported in some patients with schizophrenia, ${ }^{64,65}$ and which correlates with negative symptoms, ${ }^{66}$ may also contribute to an enhanced sensitivity to the psychotogenic effects of cannabis use. It is important to highlight in this context that most individuals who use cannabis do not develop schizophrenia. Therefore, while cannabis use is neither necessary nor sufficient for the development of schizophrenia, available evidence suggests that cannabis use may initiate the emergence of a lasting psychotic illness in some persons (most likely those individuals with a genetic vulnerability), ${ }^{67}$ and this finding warrants serious consideration from the point of view of public health policy.

It is becoming increasingly clear that acute psychosis, schizophreniform disorder, and schizophrenia are the result of interactions among many different factors operating at various levels. For example, having a close family member with schizophrenia is the strongest known risk factor for schizophrenia, yet few investigations linking cannabis use and schizophrenia have controlled specifically for familial schizophrenia risk. The results of one study ${ }^{68}$ suggested that cannabis use may lead to schizophrenia in individuals with a family history of the disease compared with those individuals without a family history. However, controlling for familial risk in one large epidemiological study ${ }^{69}$ considerably attenuated but did not completely eliminate the association of cannabis use with schizophrenia, with odds ratios of 3.3 and 1.6 with 3-year and 7-year temporal delays, respectively.

Possible 3-way interactions among genotype, cannabis use, and psychosis have also been explored. The DRD2 genotype (OMIM 126450) influenced the likelihood of a psychotic disorder in individuals who used cannabis. ${ }^{70}$ Among occasional cannabis users and daily cannabis users, carriers of the $D R D 2$, rs1076560, $T$ allele had 3 -fold and 5-fold higher likelihoods of a psychotic disorder, respectively. ${ }^{70}$ The functional COMTVal-158 polymorphism has also been reported to moderate the effect of adolescent cannabis use on adult psychosis, such that carriers of this allele were more likely to develop schizophreniform disorder if they used cannabis than noncarriers of the allele. ${ }^{67}$ In an experimental THC study, ${ }^{71}$ COMT Val carriers had greater cognitive impairment after THC exposure and more psychotic symptoms than COMT Met/Met carriers. An AKT1 genotype by cannabis use interaction has also been reported, with those individuals having C/C rs2494732 genotypes and also using cannabis having a 2-fold higher chance of experiencing a psychotic 
disorder. ${ }^{72}$ In another study, ${ }^{73}$ those participants who were carriers of the $A K T 1 \mathrm{C} / \mathrm{C}$ genotype with ever use of cannabis and daily use showed 2-fold and 7-fold increased likelihoods of a psychotic disorder, respectively, compared with users and daily users who were $\mathrm{T} / \mathrm{T}$ carriers.

The results supporting the hypothesis that some gene variants influence the likelihood of developing schizophrenia contingent on certain environmental exposure (eg, cannabis use) reflect tentative findings among small numbers of individuals that require replication. ${ }^{74}$ An alternative explanation is that individuals at genetic high risk for schizophrenia may be more likely to use cannabis through a shared genetic risk for schizophrenia and cannabis use disorder. Indeed, the recent report from a large genome-wide association study ${ }^{75}$ of an association between schizophrenia risk alleles and cannabis use suggests that part of the association between schizophrenia and cannabis use may be because of a shared genetic etiology. However, the use of cannabis with high THC potency was strongly associated with later development of schizophrenia in one study, ${ }^{63}$ while the recently reported polygenic risk score for schizophrenia ${ }^{76}$ was unrelated to cannabis use or the potency of cannabis used. ${ }^{77}$

Finally, as in chronic or heavy cannabis users, ${ }^{78}$ patients with schizophrenia also show reduced volumes in the amygdala and hippocampus. ${ }^{79}$ This observation could help explain the worse clinical outcomes in individuals with schizophrenia who use cannabis because those morphological changes are likely to underlie or contribute to the cannabis-associated exacerbation of symptoms seen in schizophrenia. ${ }^{80}$

\section{Conclusions}

Decades of ill-informed and porous legal and illegal drug regulations have exacted a devastating public health toll from our society. It is clear that the cumulative effect of nicotine exposure and alcohol use on morbidity and mortality has been staggering, as has the disproportionate criminal justice influence of the "war on drugs" on minority and disadvantaged populations. Current efforts to normalize cannabis use are being driven largely by a combination of grassroots activism, pharmacological ingenuity, and private profiteering, with a worrisome disregard for scientific evidence, gaps in our knowledge, or the possibility of unintended consequences. Given the critical and wide-ranging role of the endocannabinoid system in the brain, ${ }^{81-83}$ the increasing prevalence of cannabis use and use disorders over the last decade and the increased THC concentration in cannabis plants, there is a need to clarify which aspects of cannabis exposure (eg, age at initiation, quantity used, frequency of use, duration of use, and potency of cannabis used) confer the greatest risk for the development of cannabis use disorder or for other adverse consequences (ie, cognitive deficits, lack of motivation, or psychosis). In addition, there are many unanswered questions more directly linked to the soundness of hastily implemented policies. For example, will advertising be permitted? What patterns of use and associated toxic effects will emerge if and when "e-joints" become widespread or even the norm among adolescents? How will expanding the pool of pregnant cannabis users affect the developmental trajectories of exposed fetuses? Finally, what are the consequences of secondhand cannabis smoke?

If we stay the current course, we are likely to uncover effects that were rare in the past only because the use was not as widespread as that of legal drugs. Vulnerable populations such as children, adolescents, the elderly, or individuals with other disorders may experience novel toxic effects (as well as the potential benefits). The changing landscape of cannabis use (eg, strains with higher THC potency, new routes of administration ["vaping" and edibles], and novel drug combinations) and a culture of rapidly changing norms and perceptions raise the possibility that our current, limited knowledge may only apply to the ways in which the drug was used in the past.

The areas explored in this article, which reflect only a subset of the multiple effects of cannabis use on the brain and body, belie the ubiquity of the cannabinoid signaling system. Therefore, in addition to expanding our basic research efforts, we should try to learn as much and as rapidly as we can from the ongoing changes in local policies to minimize the harms and maximize the potential benefits.

\section{ARTICLE INFORMATION}

Submitted for Publication: October 9, 2015; final revision received December 8, 2015; accepted December 10, 2015.

Published Online: February 3, 2016. doi:10.1001/jamapsychiatry.2015.3278.

Author Affiliations: National Institute on Drug Abuse, National Institutes of Health, Bethesda Maryland (Volkow, Baler); Child Development Center, University of California, Irvine (Swanson): Center for Addiction Medicine, Department of Psychiatry, Massachusetts General Hospital, Boston (Evins); Harvard Medical School, Boston, Massachusetts (Evins); Veterans Affairs Boston Healthcare System, Harvard Medical School, Brockton, Massachusetts (DeLisi); Department of Psychology, Arizona State University, Tempe (Meier); Center for Children and Families, Department of Psychology, Florida International University, Miami (Gonzalez); Division of Psychiatry, University College London, London, England (Bloomfield); Psychiatric Imaging Group, Medical Research Council Clinical Sciences Centre,
Hammersmith Hospital, London, England (Bloomfield); Clinical Psychopharmacology Unit Clinical Health Psychology, University College London, London, England (Curran).

Author Contributions: Dr Volkow had full access to all the data in the study and takes responsibility for the integrity of the data and the accuracy of the data analysis.

Study concept and design: All authors.

Acquisition, analysis, or interpretation of data

Volkow, Swanson, Evins, DeLisi, Meier, Gonzalez, Bloomfield, Curran.

Drafting of the manuscript: All authors.

Critical revision of the manuscript for important intellectual content: All authors.

Statistical analysis: Swanson, Evins, DeLisi, Meier, Gonzalez, Bloomfield, Curran.

Obtained funding: Volkow, Swanson, Evins, DeLisi, Meier, Gonzalez, Bloomfield, Curran.

Administrative, technical, or material support: Volkow, Baler.

Conflict of Interest Disclosures: Dr Swanson reported receiving support from Alza, Richwood, Shire, Celgene, Novartis, Celltech, Gliatech,
Cephalon, Watson, CIBA, Janssen, and McNeil; reported serving on advisory boards of Alza, Richwood, Shire, Celgene, Novartis, Celltech, UCB, Gliatech, Cephalon, McNeil, and Eli Lilly; reported serving on speakers bureaus of Alza, Shire, Novartis, Celltech, UCB, Cephalon, CIBA, Janssen, and McNeil; and reported being a consultant to Alza, Richwood, Shire, Celgene, Novartis, Celltech, UCB, Gliatech, Cephalon, Watson, CIBA, Jansen, McNeil, and Eli Lilly. Dr Evins reported serving as an advisor and paid grant reviewer for the Pfizer Global Research Awards for Nicotine Dependence (GRAND) Grants Program. No other disclosures were reported.

Funding/Support: This work was financed in part by support from the following: Forum Pharmaceuticals to support grant R01 DA030992 from the National Institute of Drug Abuse and Pfizer to support grant R01 DA021245 from the National Institute of Drug Abuse (Dr Evins); National Institutes of Health Intramural Research Program (National Institute on Alcohol Abuse and Alcoholism) using the infrastructure of the Brookhaven National Laboratory under contract 
DE-AC02-98CH10886 (Dr Volkow); grant R01 DA021576 from the National Institute of Drug Abuse (Dr DeLisi); United Kingdom Medical Research Council, National Institute of Health Research, and British Medical Association (Dr Bloomfield); and a grant from the United Kingdom National Institute of Health Research Biomedical Research Council to King's College London and a United Kingdom Medical Research Council grant (Dr Curran).

Role of the Funder/Sponsor: The funding agencies did not participate in the design and conduct of the study; collection, management, analysis, and interpretation of the data; and preparation, review, or approval of the manuscript.

\section{REFERENCES}

1. Crane NA, Schuster RM, Fusar-Poli P, Gonzalez R. Effects of cannabis on neurocognitive functioning: recent advances, neurodevelopmental influences, and sex differences. Neuropsychol Rev. 2013;23(2) 117-137.

2. Crean RD, Crane NA, Mason BJ. An evidence based review of acute and long-term effects of cannabis use on executive cognitive functions. J Addict Med. 2011;5(1):1-8.

3. Ranganathan M, D'Souza DC. The acute effects of cannabinoids on memory in humans: a review. Psychopharmacology (Berl). 2006;188(4):425-444. 4. Grant I, Gonzalez R, Carey CL, Natarajan L, Wolfson T. Non-acute (residual) neurocognitive effects of cannabis use: a meta-analytic study. J Int Neuropsychol Soc. 2003;9(5):679-689.

5. Schreiner AM, Dunn ME. Residual effects of cannabis use on neurocognitive performance after prolonged abstinence: a meta-analysis. Exp Clin Psychopharmacol. 2012;20(5):420-429.

6. Solowij N. Pesa N. Cannabis and cognition: short and long term effects. In: Castle DMR, D'Souza DC, eds. Marijuana and Madness. 2nd ed. New York, NY: Cambridge University Press; 2012:91-102.

7. Lubman DI, Cheetham A, Yücel M. Cannabis and adolescent brain development. Pharmacol Ther. 2015;148:1-16.

8. O'Shea M, Singh ME, McGregor IS, Mallet PE. Chronic cannabinoid exposure produces lasting memory impairment and increased anxiety in adolescent but not adult rats. J Psychopharmacol. 2004;18(4):502-508

9. Schneider M, Schömig E, Leweke FM. Acute and chronic cannabinoid treatment differentially affects recognition memory and social behavior in pubertal and adult rats. Addict Biol. 2008;13(3-4):345-357.

10. Fontes MA, Bolla KI, Cunha PJ, et al. Cannabis use before age 15 and subsequent executive functioning. Br J Psychiatry. 2011;198(6):442-447.

11. Gruber SA, Sagar KA, Dahlgren MK, Racine M, Lukas SE. Age of onset of marijuana use and executive function. Psychol Addict Behav. 2012;26 (3):496-506

12. Meier MH, Caspi $A$, Ambler $A$, et al. Persistent cannabis users show neuropsychological decline from childhood to midlife. Proc Natl Acad Sci U S A 2012;109(40):E2657-E2664. doi:10.1073/pnas.1206820109.

13. Lorenzetti V, Solowij N, Fornito A, Lubman DI, Yucel $\mathrm{M}$. The association between regular cannabis exposure and alterations of human brain morphology: an updated review of the literature. Curr Pharm Des. 2014;20(13):2138-2167.

14. Batalla A, Crippa JA, Busatto GF, et al. Neuroimaging studies of acute effects of THC and $\mathrm{CBD}$ in humans and animals: a systematic review. Curr Pharm Des. 2014;20(13):2168-2185.

15. Weiland BJ, Thayer RE, Depue BE, Sabbineni A Bryan $A D$, Hutchison KE. Daily marijuana use is not associated with brain morphometric measures in adolescents or adults. J Neurosci. 2015;35(4):15051512

16. Zalesky A, Solowij N, Yücel M, et al. Effect of long-term cannabis use on axonal fibre connectivity. Brain. 2012;135(pt 7):2245-2255.

17. Jager G, Block RI, Luijten M, Ramsey NF. Cannabis use and memory brain function in adolescent boys: a cross-sectional multicenter functional magnetic resonance imaging study. J Am Acad Child Adolesc Psychiatry. 2010;49(6):561-572, 572.e1-572.e3. doi:10.1016/j.jaac.2010.02.001.

18. Orr C, Morioka R, Behan B, et al. Altered resting-state connectivity in adolescent cannabis users. Am J Drug Alcohol Abuse. 2013;39(6):372-381.

19. Houck JM, Bryan AD, Feldstein Ewing SW. Functional connectivity and cannabis use in high-risk adolescents. Am J Drug Alcohol Abuse. 2013;39(6):414-423.

20. Jacobsen LK, Pugh KR, Constable RT, Westerveld M, Mencl WE. Functional correlates of verbal memory deficits emerging during nicotine withdrawal in abstinent adolescent cannabis users Biol Psychiatry. 2007;61(1):31-40.

21. Morgan CJ, Schafer G, Freeman TP, Curran HV. Impact of cannabidiol on the acute memory and psychotomimetic effects of smoked cannabis: naturalistic study [published correction appears in Br J Psychiatry. 2010;197:416]. Br J Psychiatry. 2010;197(4):285-290.

22. Englund A, Morrison PD, Nottage J, et al Cannabidiol inhibits THC-elicited paranoid symptoms and hippocampal-dependent memory impairment. J Psychopharmacol. 2013;27(1):19-27.

23. Fried PA, Watkinson B, Gray R. Neurocognitive consequences of marihuana: a comparison with pre-drug performance. Neurotoxicol Teratol. 2005; 27(2):231-239.

24. Cheetham A, Allen NB, Whittle S, Simmons JG, Yücel M, Lubman DI. Orbitofrontal volumes in early adolescence predict initiation of cannabis use: a 4-year longitudinal and prospective study. Biol Psychiatry. 2012;71(8):684-692.

25. Pagliaccio D, Barch DM, Bogdan R, et al. Shared predisposition in the association between cannabis use and subcortical brain structure. JAMA Psychiatry 2015;72(10):994-1001.

26. National Institutes of Health. Adolescent Brain Cognitive Development Study. http:

//addictionresearch.nih.gov/adolescent-brain -cognitive-development-study. Published 2015. Accessed December 17, 2015.

27. Batalla $A$, Bhattacharyya S, Yücel $M$, et al Structural and functional imaging studies in chronic cannabis users: a systematic review of adolescent and adult findings. PLoS One. 2013;8(2):e55821. doi:10.1371/journal.pone.0055821.

28. Crane NA, Schuster RM, Mermelstein RJ, Gonzalez R. Neuropsychological sex differences associated with age of initiated use among young adult cannabis users. J Clin Exp Neuropsychol. 2015; 37(4):389-401.

29. Radhakrishnan R, Wilkinson ST, D'Souza DC Gone to pot: a review of the association between cannabis and psychosis. Front Psychiatry. 2014;5:54. 30. Tunbridge EM, Dunn G, Murray RM, et al. Genetic moderation of the effects of cannabis: catechol-O-methyltransferase (COMT) affects the impact of $\Delta^{9}$-tetrahydrocannabinol (THC) on working memory performance but not on the occurrence of psychotic experiences. J Psychopharmacol. 2015;29(11):1146-1151.

31. French L, Gray C, Leonard G, et al. Early cannabis use, polygenic risk score for schizophrenia and brain maturation in adolescence. JAMA Psychiatry. 2015;72(10):1002-1011.

32. Kalant OJ. Report of the Indian Hemp Drugs Commission, 1893-94: a critical review. Int J Addict. 1972;7(1):77-96.

33. Marin RS. Apathy: a neuropsychiatric syndrome. J Neuropsychiatry Clin Neurosci. 1991;3 (3):243-254

34. McGlothlin WH, West LJ. The marihuana problem: an overview. Am J Psychiatry. 1968;125 (3):126-134.

35. Silins E, Horwood LJ, Patton GC, et al; Cannabis Cohorts Research Consortium. Young adult sequelae of adolescent cannabis use: an integrative analysis. Lancet Psychiatry. 2014;1(4):286-293.

36. Paule MG, Allen RR, Bailey JR, et al. Chronic marijuana smoke exposure in the rhesus monkey, II: effects on progressive ratio and conditioned position responding. J Pharmacol Exp Ther. 1992; 260(1):210-222.

37. Lane SD, Cherek DR, Pietras CJ, Steinberg JL. Performance of heavy marijuana-smoking adolescents on a laboratory measure of motivation. Addict Behav. 2005;30(4):815-828.

38. Lane SD, Cherek DR. Marijuana effects on sensitivity to reinforcement in humans. Neuropsychopharmacology. 2002;26(4):520-529.

39. Bloomfield MA, Morgan CJ, Egerton A, Kapur S Curran HV, Howes OD. Dopaminergic function in cannabis users and its relationship to cannabis-induced psychotic symptoms. Biol Psychiatry. 2014;75(6):470-478.

40. Berridge KC, Robinson TE. What is the role of dopamine in reward: hedonic impact, reward learning, or incentive salience? Brain Res Brain Res Rev. 1998;28(3):309-369.

41. Volkow ND, Wang GJ, Telang F, et al. Decreased dopamine brain reactivity in marijuana abusers is associated with negative emotionality and addiction severity. Proc Natl Acad Sci U S A. 2014;111 (30):E3149-E3156. doi:10.1073/pnas.1411228111.

42. Garner EL. Cannabinoids and addiction. In: Pertwee R, ed. Handbook of Cannabis. Oxford, England: Oxford University Press; 2014.

43. EISohly MA. Potency Monitoring Program Quarterly Report No. 123. Oxford: National Center for Natural Products Research, University of Mississippi; 2014

44. Morgan CJ, Page E, Schaefer $C$, et al. Cerebrospinal fluid anandamide levels, cannabis use and psychotic-like symptoms. Br J Psychiatry. 2013;202(5):381-382.

45. Hirvonen J, Goodwin RS, Li CT, et al. Reversible and regionally selective downregulation of brain 
cannabinoid $\mathrm{CB}_{1}$ receptors in chronic daily cannabis smokers. Mol Psychiatry. 2012;17(6):642-649.

46. Serrano A, Parsons LH. Endocannabinoid influence in drug reinforcement, dependence and addiction-related behaviors. Pharmacol Ther. 2011; 132(3):215-241.

47. Schizophrenia Commission. The Abandoned Illness: A Report by the Schizophrenia Commission. London, England: Rethink Mental Illness; November 2012

48. Ferraro L, Russo M, O'Connor J, et al. Cannabis users have higher premorbid IQ than other patients with first onset psychosis. Schizophr Res. 2013;150 (1):129-135.

49. Large M, Sharma S, Compton MT, Slade T, Nielssen O. Cannabis use and earlier onset of psychosis: a systematic meta-analysis. Arch Gen Psychiatry. 2011;68(6):555-561.

50. Miettunen J, Törmänen S, Murray GK, et al. Association of cannabis use with prodromal symptoms of psychosis in adolescence. $\mathrm{Br} \mathrm{J}$ Psychiatry. 2008;192(6):470-471.

51. D'Souza DC, Perry E, MacDougall L, et al. The psychotomimetic effects of intravenous delta-9-tetrahydrocannabinol in healthy individuals: implications for psychosis. Neuropsychopharmacology. 2004;29(8):1558-1572 52. Arseneault L, Cannon M, Poulton R, Murray R, Caspi A, Moffitt TE. Cannabis use in adolescence and risk for adult psychosis: longitudinal prospective study. BMJ. 2002;325(7374):1212-1213.

53. Andréasson $S$, Allebeck $P$, Engström A, Rydberg U. Cannabis and schizophrenia: a longitudinal study of Swedish conscripts. Lancet. 1987;2(8574):14831486

54. Zammit $S$, Allebeck $P$, Andreasson $S$, Lundberg I, Lewis G. Self reported cannabis use as a risk facto for schizophrenia in Swedish conscripts of 1969: historical cohort study. BMJ. 2002;325(7374):1199.

55. van Os J, Bak M, Hanssen M, Bijl RV, de Graaf R, Verdoux H. Cannabis use and psychosis: a longitudinal population-based study. Am J Epidemiol. 2002;156(4):319-327.

56. Fergusson DM, Horwood LJ, Swain-Campbel NR. Cannabis dependence and psychotic symptoms in young people. Psychol Med. 2003;33(1):15-21.

57. Weiser M, Knobler HY, Noy S, Kaplan Z. Clinical characteristics of adolescents later hospitalized for schizophrenia. Am J Med Genet. 2002;114(8):949955.

58. Alvarez-Jimenez M, Priede A, Hetrick SE, et al. Risk factors for relapse following treatment for first episode psychosis: a systematic review and meta-analysis of longitudinal studies. Schizophr Res. 2012:139(1-3):116-128.

59. Foti DJ, Kotov R, Guey LT, Bromet EJ. Cannabis use and the course of schizophrenia: 10-year follow-up after first hospitalization. Am J Psychiatry 2010;167(8):987-993.

60. Di Forti M, Sallis H, Allegri F, et al. Daily use especially of high-potency cannabis, drives the earlier onset of psychosis in cannabis users. Schizophr Bull. 2014;40(6):1509-1517.

61. Galvez-Buccollini JA, Proal AC, Tomaselli V, et al. Association between age at onset of psychosis and age at onset of cannabis use in non-affective psychosis. Schizophr Res. 2012;139(1-3):157-160.

62. Di Forti M, Morgan C, Dazzan P, et al. High-potency cannabis and the risk of psychosis. Br J Psychiatry. 2009;195(6):488-491.

63. Di Forti M, Marconi A, Carra E, et al. Proportion of patients in south London with first-episode psychosis attributable to use of high potency cannabis: a case-control study. Lancet Psychiatry. 2015;2(3):233-238

64. Volk DW, Eggan SM, Horti AG, Wong DF, Lewis DA. Reciprocal alterations in cortical cannabinoid receptor 1 binding relative to protein immunoreactivity and transcript levels in schizophrenia. Schizophr Res. 2014;159(1):124-129.

65. Wong DF, Kuwabara $\mathrm{H}$, Horti $A G$, et al. Quantification of cerebral cannabinoid receptors subtype 1 (CB1) in healthy subjects and schizophrenia by the novel PET radioligand $\left[{ }^{11} C\right]$ OMAR. Neuroimage. 2010;52(4):1505-1513.

66. Wong DF, Kuwabara $\mathrm{H}$, Horti $A G$, et al. Cannabinoid receptor subtype 1 (CB1) distribution correlates with neuropsychiatric ratings. In: Proceedings from the Society of Biological Psychiatry; May 20-22, 2010; New Orleans, Louisiana.

67. Caspi A, Moffitt TE, Cannon M, et al. Moderation of the effect of adolescent-onset cannabis use on adult psychosis by a functional polymorphism in the catechol-O-methyltransferase gene: longitudinal evidence of a gene $x$

environment interaction. Biol Psychiatry. 2005;57 (10):1117-1127.

68. Proal AC, Fleming J, Galvez-Buccollini JA, Delis LE. A controlled family study of cannabis users with and without psychosis. Schizophr Res. 2014;152(1): 283-288.

69. Giordano GN, Ohlsson H, Sundquist K Sundquist J, Kendler KS. The association between cannabis abuse and subsequent schizophrenia: a Swedish national co-relative control study. Psychol Med. 2015;45(2):407-414.

70. Colizzi M, lyegbe C, Powell J, et al. Interaction between functional genetic variation of $D R D 2$ and cannabis use on risk of psychosis. Schizophr Bull. 2015;41(5):1171-1182.

71. Henquet C, Rosa A, Krabbendam L, et al. An experimental study of catechol-O- methyltransferase Val ${ }^{158}$ Met moderation of |[Delta]|-9-tetrahydrocannabinol-induced effects on psychosis and cognition. Neuropsychopharmacology. 2006;31(12):2748-2757. 72. van Winkel R, van Beveren NJ, Simons C; Genetic Risk and Outcome of Psychosis (GROUP) Investigators. AKT1 moderation of cannabis-induced cognitive alterations in psychotic disorder. Neuropsychopharmacology. 2011;36(12): 2529-2537.

73. Di Forti M, lyegbe C, Sallis $\mathrm{H}$, et al. Confirmation that the $A K T 1$ (rs2494732) genotype influences the risk of psychosis in cannabis users. Biol Psychiatry. 2012;72(10):811-816.

74. Decoster J, van Os J, Myin-Germeys I, De Hert M, van Winkel R. Genetic variation underlying psychosis-inducing effects of cannabis: critical review and future directions. Curr Pharm Des. 2012 18(32):5015-5023.

75. Power RA, Verweij KJ, Zuhair M, et al. Genetic predisposition to schizophrenia associated with increased use of cannabis. Mol Psychiatry. 2014;19 (11):1201-1204.

76. Schizophrenia Working Group of the Psychiatric Genomics Consortium. Biological insights from 108 schizophrenia-associated genetic loci. Nature. 2014:511(7510):421-427.

77. Di Forti M, Vassos E, Lynskey M, Craig M, Murray R. Data vs speculation concerning the greater risk of psychosis associated with the use of high potency cannabis [letter]. Lancet Psychiatry. 2015;2(5):382.

78. Yücel M, Solowij N, Respondek C, et al. Regional brain abnormalities associated with long-term heavy cannabis use. Arch Gen Psychiatry. 2008;65(6):694-701.

79. van Erp TG, Hibar DP, Rasmussen JM, et al Subcortical brain volume abnormalities in 2028 individuals with schizophrenia and 2540 healthy controls via the ENIGMA consortium [published online August 18, 2015]. Mol Psychiatry.

80. D'Souza DC. Cannabinoids and psychosis. Int Rev Neurobiol. 2007;78:289-326.

81. Kano M, Ohno-Shosaku T, Hashimotodani Y, Uchigashima M, Watanabe M. Endocannabinoidmediated control of synaptic transmission. Physiol Rev 2009:89(1):309-380.

82. Morena M, Patel S, Bains JS, Hill MN. Neurobiological interactions between stress and the endocannabinoid system. Neuropsychopharmacology. 2016;41(1):80-102. 83. Woodhams SG, Sagar DR, Burston JJ, Chapman V. The role of the endocannabinoid system in pain. Handb Exp Pharmacol. 2015;227:119-143. 